\title{
Suscetibilidade de linhagens celulares e cultivos primários ao Neospora caninum
}

\author{
Susceptibility of cell lines and primary cell cultures to Neospora caninum
}

\author{
Gustavo Cauduro Cadore ${ }^{\mathrm{I}}$ Fernanda Silveira Flores Vogel ${ }^{\mathrm{II}^{*}}$ Eduardo Furtado Flores ${ }^{\mathrm{II}}$

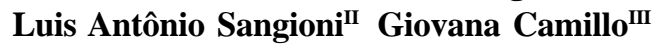

\begin{abstract}
O Neospora caninum é um protozoário de ampla distribuição e grande importância na bovinocultura, principalmente pelas perdas reprodutivas que produz. Cultivos celulares são utilizados para o isolamento e a multiplicação do agente in vitro, com diversas finalidades. Este trabalho teve como objetivo avaliar a suscetibilidade de diferentes cultivos celulares à infecção pelo $N$. caninum. Dentre oito cultivos testados, quatro apresentaram boa susceptibilidade ao $\mathrm{N}$. caninum: células VERO (produção de 21,2 taquizoítos/célula), MA-104 (17,1), cultivo primário de testículo $(16,3)$ e pulmão bovino $(13,6)$. Cultivo primário de rim bovino $(8,2)$, células MDBK $(5,1)$ e RK-13 $(0,4)$ apresentaram baixa sensibilidade, enquanto células MDCK não produziram taquizoítos viáveis. Os resultados obtidos demonstram que as células MA-104 apresentaram suscetibilidade semelhante a das células VERO - linhagem tradicionalmente utilizada para o cultivo desse protozoário. Pela maior facilidade de cultivo, rápida multiplicação, menor exigência nutricional e produção de taquizoítos em níveis semelhantes às células VERO, as células MA-104 demonstraram ser adequadas para a manutenção $e$ multiplicação do $N$. caninum in vitro.
\end{abstract}

Palavras-chave: Neospora caninum, cultivo celular, diagnóstico, células VERO, células MA104.

\section{ABSTRACT}

Neospora caninum is a protozoan of wide distribution and great importance to the cattle industry, mainly due to its associated reproductive losses. Cultured cells are widely used for isolation and multiplication of the agent in vitro with several purposes. Thus, this study aimed to evaluate the susceptibility of different cell cultures to infection by $\mathbf{N}$. caninum. Among the cell cultures tested, four presented good susceptibility to the agent: cell lines VERO (yield of 21.2 taquizoites/cell) and MA-104 (17.1); primary bovine testicle (16.3) and lung cells (13.6). Primary bovine kidney (8.2 taquizoites/cell), MDBK (5.1) and RK-13 cell lines (0.4) presented moderate to low sensitivity. No viable taquizoites were detected in the culture of MDCK cells. These results demonstrate that MA-104 cells present adequate susceptibility to $N$. caninum compared to VERO cells, which have been largely used to multiply the parasite in vitro. Together with its easy manipulation, fast multiplication and relatively low nutritional requirements, these results indicate that MA-104 cells are adequate for multiplication of $N$. caninum in vitro.

Key words: Neospora caninum, tissue culture, diagnostic, VERO, MA-104.

A neosporose é uma doença causada pelo protozoário intracelular Neospora caninum (Apicomplexa, Sarcocystidae), relatado inicialmente em cães, na Noruega (BJERKAS et al., 1984). Desde então, esse agente tem sido descrito em várias espécies animais, incluindo ruminantes (DUBEY \& LINDSAY, 1996). Em bovinos, a infecção é caracterizada por perdas reprodutivas em fêmeas, podendo resultar em mortalidade embrionária durante o primeiro terço gestacional e abortos durante o segundo trimestre. No terço final da gestação, a infecção geralmente não

IPrograma de Pós-graduação em Medicina Veterinária, Universidade Federal de Santa Maria (UFSM), Santa Maria, RS, Brasil.

IIDepartamento de Medicina Veterinária Preventiva (DMVP), Centro de Ciências Rurais (CCR), UFSM, 97105-900, Santa Maria RS, Brasil. E-mail: fervogel@smail.ufsm.br.*Autor para correspondência.

IIICurso em Medicina Veterinária, UFSM, Santa Maria, RS, Brasil. 
acarreta morte fetal e abortos, mas sim a produção de bezerros saudáveis, porém persistentemente infectados, o que também pode ocorrer no segundo terço da gestação (DUBEY, 2003). Na maioria dos animais, a infecção não induz imunidade protetora, e as conseqüências reprodutivas da infecção podem ocorrer repetidas vezes durante a vida dos animais infectados (MORALES et al., 2001; GARCIAVAZQUEZ et al., 2002).

O ciclo biológico do $N$. caninum foi esclarecido por MCALLISTER et al. (1998) e envolve hospedeiros definitivos e intermediários. Os primeiros abrigam o agente e se caracterizam por excretar oocistos nas fezes, os quais esporulam no ambiente e são infectantes para os hospedeiros intermediários. Estes, por sua vez, ingerem os oocistos esporulados e desenvolvem cistos teciduais. O protozoário consegue se disseminar nos rebanhos por transmissão horizontal, por meio da ingestão de oocistos excretados pelos hospedeiros definitivos, após a esporulação no meio ambiente. A transmissão vertical, da vaca gestante para o feto, assume papel importante na manutenção do protozoário em rebanhos, pois a maioria das infecções congênitas resulta no nascimento de bezerros persistentemente infectados (TREES \& WILLIAMS, 2005).

O controle e a profilaxia da Neosporose Bovina dependem de técnicas de diagnóstico adequadas, para a identificação dos animais portadores e para o diagnóstico de perdas reprodutivas pelo agente. Várias técnicas têm sido utilizadas com essa finalidade, tanto para diagnóstico, quanto em pesquisa, para estudos de patogenia e estudos soroepidemiológicos. Nesse sentido, os cultivos celulares são de grande importância, tanto para isolamento e diagnóstico do agente, quanto para a sua multiplicação in vitro com diversas finalidades. A realização da técnica de imunofluorescência indireta, por exemplo, é dependente da multiplicação do agente em cultivos (DUBEY, 2003; HEMPHILL et al., 2004).

A linhagem celular VERO (African Green monkey kidney) é a mais utilizada para a propagação do agente in vitro (DUBEY, 2003). No entanto, o cultivo dessas células por vezes apresenta dificuldades, principalmente no que se refere à velocidade de multiplicação e ao nível de exigência de componentes nutricionais do meio de cultivo. Por isso, a disponibilidade de outros cultivos celulares suscetíveis ao parasita seria de grande interesse e utilidade para o diagnóstico e pesquisa do $N$. caninum. Assim, este trabalho teve por objetivo testar a suscetibilidade de diferentes linhagens celulares e cultivos primários ao N. caninum.
Para isso, taquizoítos da cepa NC-1 do $N$. caninum (gentilmente cedida pela Dra. Solange Gennari, USP) foram inoculados em oito cultivos celulares: cultivo primário de rim, pulmão e testículo bovino; células MDBK (Madin Darby bovine kidney), MDCK (Madin Darby canine kidney), RK-13 (rabbit kidney), MA-104 (African Green Monkey kidney cells) e VERO (African Green Monkey kidney cells).

Os cultivos primários foram produzidos a partir de tecidos obtidos de um feto bovino coletado em frigorífico, segundo FRESHNEY (1987). As células MDBK, MDCK, RK-13, MA-104 e VERO pertenciam ao Laboratório de Virologia da Universidade Federal de Santa Maria. Cada cultivo celular foi mantido em garrafas plásticas de $25 \mathrm{~cm}^{2}$, em MEM (meio essencial mínimo), exceto as células VERO (mantidas em RPMI), sendo todas suplementadas com $10 \%$ de soro fetal bovino. Quando o tapete de células atingia sua confluência, eram realizadas contagens do número de células por garrafa (células por $\mathrm{cm}^{2}$ ), para isso, as células eram tripsinizadas e diluídas em solução contendo azul de trypan com a contagem realizada em câmara de Neubauer, segundo recomendações de FRESHNEY (1987). Para cada cultivo celular, foram realizadas três contagens, sendo o resultado expresso em uma média.

Para avaliação da suscetibilidade de cada cultivo, as células foram inoculadas com o título final de $5 \times 10^{5}$ taquizoítos para cada cultivo testado. Alíquotas de cada cultivo inoculado foram coletadas nos dias cinco, seis e sete após a infecção para contagem do número de taquizoítos. A produção de taquizoítos foi avaliada em triplicata (três cultivos independentes, com três contagens de taquizoítos cada), nas células RK-13, MA-104, MDBK, MDCK e VERO; e em duplicata, nos cultivos primários (dois experimentos, três contagens de taquizoítos cada). A contagem dos taquizoítos foi realizada em câmara de Neubauer, e o resultado foi expresso em número médio de taquizoítos por $0,2 \mathrm{~mL}$, que correspondem a $1 \mathrm{~cm}^{2}$ do tapete celular. Os valores médios da produção de taquizoítos nas três (ou duas) repetições para cada dia estão apresentados na tabela 1, os valores médios com seus respectivos desvios-padrão estão apresentados na tabela 2.

Dos cultivos testados, o que apresentou maior susceptibilidade foi o de células VERO (produção média de 21,2 taquizoítos/célula, mensurado no dia 7), seguido pelas células MA-104 $(17,1)$, do cultivo primário de testículo $(16,3)$ e pulmão bovino $(13,6)$. Pela produção de taquizoítos em títulos semelhantes, esses quatro cultivos mostram-se adequados à multiplicação e manutenção da cepa NC-1. Por outro lado, o cultivo 
Tabela 1 - Média da produção de taquizoítos, em 0,2mL, do Neospora caninum, em diferentes cultivos celulares aos cinco, seis e sete dias após a inoculação, por repetição.

\begin{tabular}{|c|c|c|c|c|c|c|c|c|}
\hline & $\begin{array}{l}\text { Primário de } \\
\text { rim bovino }\end{array}$ & $\begin{array}{c}\text { Primário de } \\
\text { pulmão } \\
\text { bovino }\end{array}$ & $\begin{array}{c}\text { Primário de } \\
\text { testículo } \\
\text { bovino }\end{array}$ & $\begin{array}{l}\text { Células } \\
\text { VERO }\end{array}$ & $\begin{array}{l}\text { Células } \\
\text { MDBK }\end{array}$ & $\begin{array}{c}\text { Células MA- } \\
104\end{array}$ & $\begin{array}{c}\text { Células RK- } \\
13\end{array}$ & $\begin{array}{l}\text { Células } \\
\text { MDCK }\end{array}$ \\
\hline \multicolumn{9}{|c|}{ Dia 5} \\
\hline $\mathrm{E} 1^{a}$ & $2^{b}$ & 2 & 1,5 & 4,5 & 0,8 & 2,3 & $---{ }^{c}$ & 3,5 \\
\hline E2 & 1,5 & 2 & 2,5 & 5 & 1,2 & 2 & ---- & 5,8 \\
\hline E3 & $\mathrm{NR}^{d}$ & NR & NR & 6 & 0,5 & 2,3 & ---- & 4,7 \\
\hline \multicolumn{9}{|c|}{ Dia 6} \\
\hline E1 & 4,2 & 3,7 & 3,7 & 8,2 & 4,2 & 7 & ---- & ---- \\
\hline E2 & 3,5 & 4,2 & 2,8 & 8,2 & 4,2 & 6,2 & 0,5 & ---- \\
\hline E3 & NR & NR & NR & 7,5 & 5,2 & 7,7 & 0,5 & ---- \\
\hline \multicolumn{9}{|c|}{ Dia 7} \\
\hline E1 & 17 & 18 & 16 & 17 & 8,7 & 14 & 1,5 & ---- \\
\hline E2 & 19 & 20 & 14 & 16 & 9 & 12 & 1,3 & ---- \\
\hline E3 & NR & NR & NR & 18 & 8,3 & 13 & 0,8 & ---- \\
\hline
\end{tabular}

${ }^{a}$ Número de repetições para cada cultivo celular. Experimento 1 (E1). Os resultados para cada dia estão expressos na média das três contagens realizadas.

${ }^{b}$ Valor encontrado deve ser multiplicado por $10^{4 \mathrm{~b}}$ Contagem negativa.

${ }^{d}$ Não realizado.

primário de rim bovino $(8,2)$, células MDBK $(5,1)$ e RK$13(0,4)$ apresentaram moderada a baixa suscetibilidade, não sendo indicados para a multiplicação dessa cepa do protozoário, bem como as células MDCK, que não produziram taquizoítos viáveis
A utilização de cultivos celulares altamente susceptíveis ao $N$. caninum é indispensável, tanto para o diagnóstico, quanto para a pesquisa. Os cultivos celulares permitem a manutenção e multiplicação dos taquizoítos desse protozoário, assim como o estudo

Tabela 2 - Produção média de taquizoítos do Neospora caninum ${ }^{a}$ em diferentes cultivos celulares e desvio padrão (sd) aos cinco, seis e sete dias após a inoculação.

\begin{tabular}{|c|c|c|c|c|c|}
\hline \multirow{2}{*}{ Cultivo } & \multirow{2}{*}{$\begin{array}{l}\text { № de células } \mathrm{cm}^{-2} \\
\qquad\left(\mathrm{n} \times 10^{4}\right)\end{array}$} & \multicolumn{3}{|c|}{--------Taquizoítos/0,2mL ( n x 104) (sd) ------- } & \multirow{2}{*}{ № taquizoítos / célula ${ }^{b}$} \\
\hline & & Dia 5pi & Dia 6pi & Dia 7pi & \\
\hline Primário de rim bovino & 2,2 & $\begin{array}{c}1,7 \\
(0,2)\end{array}$ & $\begin{array}{c}3,8 \\
(0,3)\end{array}$ & $\begin{array}{c}18 \\
(0,7)\end{array}$ & 8,2 \\
\hline Primário de pulmão bovino & 1,4 & $\begin{array}{c}2 \\
(---)\end{array}$ & $\begin{array}{c}4 \\
(0,2)\end{array}$ & $\begin{array}{c}19 \\
(0,7)\end{array}$ & 13,6 \\
\hline Primário de testículo bovino & 0,9 & $\begin{array}{c}2 \\
(0,2)\end{array}$ & $\begin{array}{c}3,3 \\
(0,4)\end{array}$ & $\begin{array}{c}15 \\
(0,7)\end{array}$ & 16,3 \\
\hline Células VERO & 0,8 & $\begin{array}{c}5,2 \\
(0,6)\end{array}$ & $\begin{array}{c}8 \\
(0,3)\end{array}$ & $\begin{array}{c}17 \\
(0,4)\end{array}$ & 21,2 \\
\hline Células MDBK & 1,7 & $\begin{array}{c}0,8 \\
(0,2)\end{array}$ & $\begin{array}{c}4,5 \\
(0,4)\end{array}$ & $\begin{array}{c}8,7 \\
(0,2)\end{array}$ & 5,1 \\
\hline Células MA-104 & 0,8 & $\begin{array}{c}2,2 \\
(0,1)\end{array}$ & $\begin{array}{c}7 \\
(0,5)\end{array}$ & $\begin{array}{c}13 \\
(0,4)\end{array}$ & 17,1 \\
\hline Células RK-13 & 3,4 & ----- & $\begin{array}{c}0,5 \\
(----)\end{array}$ & $1,2(0,3)$ & 0,4 \\
\hline Células MDCK & 2,4 & $\begin{array}{c}4,7 \\
(0,8)\end{array}$ & ----- & ----- & ----- \\
\hline
\end{tabular}

${ }^{a}$ Estimada pela contagem comparativa do número de células e da quantidade de taquizoítos obtidos nos dias cinco, seis e sete após inoculação (pi).

${ }^{\mathrm{b}}$ Para essa relação, foi considerado que $0,2 \mathrm{~mL}$ correspondem a $1 \mathrm{~cm}^{2}$. Contagem realizada no dia sete.

Ciência Rural, v.39, n.5, ago, 2009. 
de características celulares, estruturais e moleculares do agente (HEMPHILL et al., 2004). Assim como o Toxoplasma gondii, o cultivo do $\boldsymbol{N}$. caninum pode utilizar diferentes tipos de células, incluindo cultivos primários e linhagens celulares, e a susceptibilidade das células ao protozoário pode variar conforme a origem das células (HEMPHILL, 1999). Cultivos de células VERO, de células endoteliais da artéria aorta e queratinócitos de murinos, já foram utilizados para a multiplicação do N. caninum (HEMPHILL et al., 2004). O cultivo de células VERO é o mais utilizado na rotina para o cultivo do N. caninum in vitro (DUBEY, 2003).

LEI et al. (2005) avaliaram a capacidade do $N$. caninum de infectar quatro cultivos celulares (linhagem de fibroblasto canino, fibroblasto canino, células VERO e células de rim de felinos), por meio do monitoramento dos cultivos infectados pela técnica de imunofluorescência. Os resultados demonstraram que esse protozoário foi capaz de invadir esses diferentes tipos de cultivos celulares. No entanto, esses autores não avaliaram a utilização desses cultivos para produção e manutenção desse protozoário.

A hipótese inicial do presente estudo era de que os cultivos primários pudessem apresentar uma suscetibilidade maior à infecção, o que resultaria em títulos superiores, - por possuírem um fenótipo semelhante ao das células do hospedeiro. No entanto, os resultados obtidos demonstraram que as linhagens VERO e MA-104 produziram maior número de taquizoítos/célula. Isso pode ser explicado pelo fato de a cepa NC-1 estar adaptada ao cultivo de células VERO. Assim, para a multiplicação dessa cepa de $\boldsymbol{N}$. caninum para diversas finalidades, podem ser utilizadas tanto as células VERO, quanto as MA-104. O cultivo primário de células de testículo de bovino utilizado neste estudo produziu quantidades consideráveis de taquizoítos etambém pode ser utilizado com essa finalidade. Dentre esses três cultivos, a escolha dependerá da facilidade de manutenção e manipulação dessas células in vitro. Nesse quesito, a escolha provavelmente recairá nas células de linhagem (VERO e MA-104). Nas condições do laboratório onde foi realizado o estudo, as células MA-104 têm apresentado um padrão de multiplicação mais constante e, por isso, têm sido adotadas para a multiplicação do parasita.

Cabe ressaltar que os estudos de suscetibilidade foram realizados com uma cepa já adaptada em linhagens celulares. Os resultados desses testes não se aplicam necessariamente a isolados de campo, que podem potencialmente se multiplicar em níveis diferentes de acordo com o cultivo utilizado. Assim, com a finalidade de isolamento, recomenda-se testar a suscetibilidade destes e de outros cultivos a isolados de campo ainda não adaptados ao cultivo in vitro. É possível que amostras de campo se multipliquem com mais eficiência em células primárias. Dessa forma, estudos posteriores são necessários para a validação de cultivos primários, para o isolamento de amostras de campo.

Em resumo, os resultados obtidos neste estudo demonstram que os cultivos de células VERO e MA-104 apresentaram maior suscetibilidade do que os demais, sendo indicados para a multiplicação in vitro da cepa NC-1. Nesse sentido, as células MA-104 se apresentam como alternativa viável para o cultivo do parasita in vitro.

\section{AGRADECIMENTOS}

Ao professor Rudi Weiblen, por disponibilizar o Laboratório de Virologia da Universidade Federal de Santa Maria para a realização deste trabalho. Ao Conselho Nacional de Desenvolvimento Científico e Tecnológico (CNPq), pela bolsa PIBIC concedida para Giovana Camillo.

\section{REFERÊNCIAS}

BJERKAS, I. et al. Unidentified cyst-forming sporozoan causing encephalomyelitis and myositis in dogs. Zeitschrift für Parasitenkunde, v.70, p.271-274, 1984.

DUBEY, J.P.; LINDSAY, D.S. A review of Neospora caninum and neosporosis. Veterinary Parasitology, v.67, p.1-59, 1996. Disponível em: <http://www.sciencedirect.com/ science?_ob=ArticleURL\&_udi=B6TD7-3RG55DF$10 \& \_u s e r=687358 \&$ _rdoc $=18 \_$fmt $=$\&_orig $=$search\&_sort $=\mathrm{d} \&$ view $=$ c \&_a c c t $=$ C $000037899 \&$ _version $=1$ \&_url Ver s i o n $=0$ \&_u s e r i d $=6 \begin{array}{lllllll}6 & 8 & 3 & 5 & \text { \& m d } 5\end{array}$ $=2757543478 \mathrm{da} 32 \mathrm{~d} 381 \mathrm{~d} 55 \mathrm{da} 60 \mathrm{a} 0 \mathrm{~d} 2 \mathrm{~b} 6 \mathrm{~b}>$. Doi:10.1016/ S0304-4017(96)01035-7.

DUBEY, J.P. Review of Neospora caninum and neosporosis in animals. Korean Journal Parasitology, v.41, n.1, p.1-16, 2003.

FRESHNEY, R.I. Culture of animal cells: a manual of basic techniques. 2.ed. New York: Wiley-Liss, 1987. 397p.

GARCIA-VAZQUEZ, Z. et al. Serological survey of Neospora caninum infection in dairy cattle herds in Aguascalientes, Mexico. Veterinary Parasitology, v.106, p.115-120, 2002. Disponível em: <http:// w w w. s c i e $n$ c e d i r e c t c c m / science?_ob=ArticleURL\&_udi=B6TD7-45C02HR$8 \&$ \&user $=687358 \& \_r d o c=1 \& \_$fmt $=$\&_orig $=$search $\&$ sort $=$ d $\&$ vie $\mathrm{w}=\mathrm{c} \&$ \& acct $=\mathrm{C} 000037899 \&$ \&version $=1 \&$ \&_urlVersion $=0 \&$ _ u s e r i d $=687358 \&$ m d $5=5$ a f d 2 d 6032fe97e99d23564314288cb2>. Doi:10.1016/S03044017(02)00040-7.

HEMPHILL, A. The host-parasite relationship in neosporosis. Advances in Parasitology, v.43, p. 47-104, 1999.

HEMPHILL, A. et al. Tissue culture and explant approaches to studying and visualizing Neospora caninum and its 
interactions with the host cell. Microscopy Microanalysis, v.10, p.602-620, 2004. ??? doi: 10.1017/ S1431927604040930.

LEI, Y. et al. Attachment and invasion of Toxoplasma gondii and Neospora caninum to epithelial and fibroblast cell lines in vitro. Parasitology, v.131, p.583-590, 2005.

MCALLISTER, M.M. et al. Dogs are definitive hosts of Neospora caninum. International Journal of Parasitology, v.28, n.9, p.1473-1478, 1998 . Disponível em: <http:// www.scopus.com/scopus/record/display.url?eid=2-s2.00031841528 \& vie w = b a sic \& ori gi n = in wa rd\&txGid=sHeVeP0JoSe0tPdDVQZ7Dyx\%3a5>. Doi: 10.1016/ S0020-7519(98)00138-6.

MORALES, E. et al. Neosporosis in Mexican dairy herds: lesions and immunohistochemical detection of Neospora caninum in fetuses. Journal Comparative Pathology, v.125, p.58-63, 2001. Disponível em: <http://www.sciencedirect.com/ science?_ob=ArticleURL\&_udi=B6WHW-45B65C5$P \& \_u s e r=687358 \& \_r d o c=1 \& \_f m t=\& \_$orig $=$search \&_sort $=d$ $\&$ view $=$ c\&_acct $=$ C $000037899 \&$ \& version $=1 \&$ \& urlV ersion $=0 \& \_$userid $=687358 \& m d 5=3212 a 021 f 5 c 72459 e 3245 b 368 f 7 e e 483>$. Doi: 10.1053/jcpa.2001.0477.

TREES, A.J., WILLIAMS, D.J. Endogenous and exogenous transplacental infection in Neospora caninum and Toxoplasma gondii. Trends in Parasitology, v.21, p.558561, 2005. Disponível em: <http://www.sciencedirect.com/ science?_ob=ArticleURL\&_udi=B6W7G-4H9GRK6$3 \&$ \& u s e r $=687358 \&$ \& r d o c $=1 \&$ 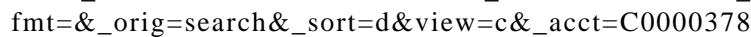 $99 \&$ \& versio n $=1 \&$ _ u r l ve r s i o n $=0 \&$ userid $=687358 \& \mathrm{md} 5=$ =83ae56d2921dce4bd9676f59a72fd85> Doi:10.1016/j.pt.2005.09.005. 